\title{
Yenidoğan yoğun bakım ünitelerinden izole edilen gram negatif bakterilerin antibiyotik duyarlılığındaki iki yıllık değişim (2014-2015)
}

\section{Antimicrobial resistance patterns of gram negative bacteria isolated from intensive care units (2014 and 2015)}

\author{
Yeliz TANRIVERDi ÇAYCI ${ }^{1 a}$, Kübra HACIEMINOĞLU' ${ }^{1}$ Asuman BiRINCi ${ }^{1}$
}

'Ondokuz Mayıs Üniversitesi Tıp Fakültesi, Tıbbi Mikrobiyoloji Anabilim Dalı, Samsun, TÜRKIYE

\section{öz}

Amaç: Çalışmanın amacı hastanemiz yenidoğan yoğun bakım ünitesi'nde (YYBÜ) yatan hastalardan 2014 ve 2015 yılları içerisinde gönderilen materyallerin kültür sonuçlarının retrospektif olarak değerlendirilmesidir.

Gereç ve Yöntemler: Hastalardan alınan örneklerin kültür sonuçları çalışma kapsamında incelendi. İzole edilen bakterilerin identifikasyonu konvansiyonel yöntemlerle veya Vitek MS 2 cihazı ile; antibiyotik duyarlılıkları ise Clinical and Laboratory Standard Instute (CLSI) önerileri doğrultusunda yine Vitek MS 2 cihazı ile çalışıldı.

Bulgular: YYBÜ'deki hastalardan gönderilen 297 materyalin 133'ü (\%38) kan örneği, 55'i (\%18,5) trakeal aspirat kültürü, 48'i $(\% 16,2)$ konjunktiva, 31'i (\%10,4) idrar kültürü, 24'ü (\%8) beyin omurilik sıvısı, 12'si (\%4) yara kültürü, 9'u (\%3) kateter ve $5^{\prime} \mathrm{i}(\% 1,7)$ steril vücut sıvısıdır. İzole edilen gram negatif bakteriler içinde $\% 28,6$ ile Klebsiella pneumoniae \%23,9 ile Acinetobacter baumanii en çok izole edilen bakterilerdir.

Sonuçlar: Enterobacteriacea üyesi bakterilerde karbapenem direnci düşüktür. Acinetobacter suşlarında karbapenemlere karşı direncin yüksek olduğu tespit edilmiştir. Yine Acinetobacter suşlarının trimetoprim-sulfametoksazole karşı düşük direnç göstermeleri göze çarpmıştır.

Anahtar Kelimeler: Yenidoğan yoğun bakım, gram negatif bakteriler, antibiyotik duyarlılığı.

Corresponding Authora: Yeliz Tanrıverdi Çaycı, MD. Ondokuz Mayıs Üniversitesi Tıp Fakültesi, Tıbbi Mikrobiyoloji Anabilim Dalı, 1. Kat, Atakum/ Samsun, TURKEY 


\section{ABSTRACT}

Aim: The aim of this study was to evaluate the culture results of patients hospitalized in the neonatal intensive care unit (NICU) at our hospital during 2014 and 2015.

Material and Methods: In this study, the cultures results of the patients were analyzed. Identification of bacteria was performed by conventional methods or Vitek MS 2 and antibiotic susceptibility tests were done by Vitek 2 MS according to the Clinical and Laboratory Standards Institute (CLSI) guidelines.

Results: 297 materials sent from NICU consisted of 133 (38\%) blood cultures, 55 (18.5\%) tracheal aspirates, 48 (16.2\%) conjunctivas, 31 (10.4\%) urine cultures, 24 (8\%) cerebrospinal fluids, 12 (4\%) wound cultures, 9 (3\%) catheter tip cultures and $5(1.7 \%)$ sterile body fluids. Klebsiella pneumoniae (28.6\%) and Acinetobacter baumanii (23.9\%) were the most frequently isolated bacteria.

Conclusion: Carbapenem resistance was low for Enterobacteriaceae species. Carbapenem resistance was high and trimethoprim-sulfamethoxazole resistance was very low for Acinetobacter baumanii

Keywords: Neonatal intensive care unit, gram negative bacteria, antibiotic susceptibility

\section{Giriş}

Enfeksiyonların en sık görüldüğü ve antibiyotiklerin en yaygın olarak kullanıldığı birimler yoğun bakım üniteleri (YBÜ)'dir. Yoğun bakım üniteleribakterilerdeantibiyotik direncinin ortaya çıkmasında ve yayılmasında en büyük paya sahip ortamlardır [1]. Yenidoğanlarda enfeksiyon anneden vertikal geçişle veya doğum sırasında/sonrasında çevreden kaynaklanan mikroorganizmalarla gelişir [2]. Yenidoğan bebeklerin immün sisteminin immatür olması, venöz, üriner ve arteriyel kateterlerin fazla kullanılması, bu bebeklerin ventilatöre daha fazla bağlanması ve ventilatörde kalma sürelerinin daha uzun olması gibi nedenler bakterilerin üremesini kolaylaştırır [3]. Bakteriyel enfeksiyonlar yenidoğanlarda önemli morbidite ve mortalite nedenidir. Bu nedenle yenidoğan yoğun bakım ünitesinin enfeksiyon etkenleri ve antimikrobiyal direnç durumunun bilinmesi rasyonel antibiyotik kullanımı açısından çok önemlidir [4]. Yoğun bakım enfeksiyon etkenleri arasında dirençli gram-pozitif koklar ve kandidaların oranı dikkate değer bir artış göstermiş olsada; Enterobacteriaceae üyeleri ve gram-negatif nonfermentatif basiller enfeksiyonların oluşumunda hala önemli bir yere sahiptir. Birçok araştırma Klebsiella pneumoniae, Escherichia coli ve Enterobacter türlerinin ve bunlara ek olarak Pseudomonas aeruginosa ve Acinetobacter türlerinin YBÜ enfeksiyonlarında en sık görülen bakteriler arasında olduğunu ortaya koymuştur [5-10].

Bu çalışmada YYBÜ enfeksiyonlarında en önemli etkenler olan gram negatif bakterilerin çeşitli antibiyotiklere karşı olan direnç profillerinin incelenmesi amaçlanmıştır.

\section{Gereç ve Yöntemler}

Yenidoğan yoğun bakım ünitelerinde 2014-2015 yılları arasında yatan hastalardan laboratuvarımıza gönderilen örneklerden izole edilen izolatlar incelenmiştir. Örnekler, kanlı agar, eosin metilen blue agar (EMB) veya çukulatamsı agara ekilmiş, $37^{\circ} \mathrm{C}$ de 24 saat inkübe edilmiştir. İnkübasyon süresi sonunda üremesi olan, izole edilen suşlar çalışmaya dahil edilmiştir. İzole edilen suşlar Vitek MS (Bio merieux, Fransa) cihazı ile tanımlanmıştır. Tanımlanan suşların antibiyotik duyarlılıkları Vitek 2 Compakt (Bio merieux, Fransa) cihazı kullanılarak saptanmıştır.

\section{Bulgular}

Gönderilen örneklerden 297 Gram negatif bakteri izole edilmiştir. En sık izole edilen bakteriler, tüm bakterilerin 201'i $(\% 67,7)$ olan Enterobacteriaecea bakterileridir. Bu bakteriler içerisinde de en sık izoleedilen bakteri 85'ini (\%28,6) oluşturan Klebsiella pneumoniae'dır. Tüm bakteri suşlarının sayıları ve yüzdeleri Tablo 1'de gösterilmiştir.

\begin{tabular}{|l|l|}
\hline \multicolumn{2}{|l|}{ Tablo 1. Klinik örneklerden izole edilen bakterilerin dağılımı } \\
\hline Bakteri & $\mathbf{n}(\%)$ \\
\hline Enterobacteriaecea & $201(\% 67,7)$ \\
\hline Acinetobacter spp. & $71(\% 23,9)$ \\
\hline Stenotrophomonas maltophilia & $13(\% 4,4)$ \\
\hline Pseudomonas aeruginosa & $11(\% 3,8)$ \\
\hline Haemophilus influenza & $1(\% 0,34)$ \\
\hline
\end{tabular}

Bakterilerin en sık elde edildiği örnek türlerinin kan kültürleri ve trakeal aspirat kültürleri olduğu saptanmıştır. Örneklerin, 133'ünü (\%38) kan kültürleri ve 55'ini $(\% 18,5)$ trakeal aspirat kültürü oluşturmaktadır. Tüm materyaller ve adetleri Tablo 2'de gösterilmiştir. 


\begin{tabular}{|l|l|}
\hline Tablo 2. Klinik örneklerin dağılımı & \\
\hline Örnek türü & n (\%) \\
\hline Kan & $113(\% 38)$ \\
\hline TAK & $55(\% 18)$ \\
\hline Konjunktiva & $48(\% 16,2)$ \\
\hline İdrar & $31(\% 10,4)$ \\
\hline BOS & $24(\% 8)$ \\
\hline Yara & $12(\% 4)$ \\
\hline Kateter & $9(\% 3)$ \\
\hline Steril vücut sıvıSI & $5(\% 1,7)$ \\
\hline
\end{tabular}

Örnek türlerine göre en çok izole edilen bakteriler belirlenmiştir. Kan kültürlerinden en çok izole edilen bakterinin $\quad(38, \% 33,6)$ $\mathrm{K}$. pneumoniae, trakeal aspirat kültürlerinde en çok izole edilen bakterinin $(21, \% 38,2)$ A. baumanii olduğu saptanmıştır.Materyallere göre en çok izole edilen bakteriler Tablo 3'te gösterilmiştir.

\begin{tabular}{|l|l|}
\hline \multicolumn{2}{|l|}{ Tablo 3. Materyallere göre en çok izole edilen bakterilerin dağlımı } \\
\hline Materyal & En çok izole edilen bakteri, $\mathbf{n}(\%)$ \\
\hline Kan kültürü & K. pneumoniae, 38 $(\% 33,6)$ \\
\hline Trakeal aspirat kültürü & A. baumanii, $21(\% 38,2)$ \\
\hline Konjunktiva & A. baumanii, 16 $(\% 33,3)$ \\
\hline İdrar kültürü & E. coli, 13 $(\% 41,9)$ \\
\hline BOS & K. pneumoniae, 10 $(\% 41,7)$ \\
\hline Yara kültürü & K. pneumoniae, 5 $(\% 41,7)$ \\
\hline Kateter & K. pneumoniae, 4 $(\% 44,4)$ \\
\hline Steril vücut sıvıSı & K. pneumoniae, 2 $(\% 40)$ \\
\hline
\end{tabular}

Enterobacteriacea üyesi bakterilerde en düşük duyarlılıkampisiline karşı olup \%3,5 olarak bulunmuştur. Bu bakterilerde en yüksek duyarlıık meropeneme $(\% 92,5)$ karşı saptanmıştır (Tablo 4).

\begin{tabular}{|c|c|c|}
\hline \multirow{2}{*}{ Enterobacteriaecea } & \multicolumn{2}{|c|}{ Duyarlı suş } \\
\hline & $\mathrm{n}$ & $(\%)$ \\
\hline Amikasin & 180 & 89,5 \\
\hline Amoksisilin/Klavulanat & 55 & 27,4 \\
\hline Ampisilin & 7 & 3,5 \\
\hline Ertapenem & 69 & 85,2 \\
\hline Imipenem & 175 & 88,4 \\
\hline Meropenem & 186 & 92,5 \\
\hline Seftazidim & 107 & 58,1 \\
\hline Seftriakson & 117 & 60 \\
\hline Siprofloksasin & 169 & 84,9 \\
\hline Trimethoprim/Sulfamethoxazol & 159 & 79,9 \\
\hline
\end{tabular}

Acinetobacter suşlarında en düşük duyarlılıkampisilin-sulbaktam, sefepim ve seftazidime karşı olup üçünde de \%12,7'dir. Bunların yanısıra trimetrophim-sulfametaksazol duyarlıı̆ı \%94,4 ve kolistin duyarlıı̆ı̆ da \%100 olarak tespit edilmiştir (Tablo 5).

\begin{tabular}{|c|c|c|}
\hline \multirow{2}{*}{$\begin{array}{l}\text { Acinetobacter baumanii } \\
71 \text { adet }\end{array}$} & \multicolumn{2}{|c|}{ Duyarlı suş } \\
\hline & $\mathrm{n}$ & (\%) \\
\hline Amikasin & 16 & 22,5 \\
\hline Ampisilin/Sulbaktam & 8 & 12,7 \\
\hline Imipenem & 10 & 14,3 \\
\hline Kolistin & 71 & 100 \\
\hline Meropenem & 11 & 15,5 \\
\hline Sefepim & 8 & 12,7 \\
\hline Sefoperazon/Sulbaktam & 14 & 22,2 \\
\hline Seftazidim & 8 & 12,7 \\
\hline Siprofloksasin & 11 & 15,5 \\
\hline Tigesiklin & 49 & 80,3 \\
\hline Trimethoprim/Sulfamethoxazol & 67 & 94,4 \\
\hline
\end{tabular}

S. maltophilia suşlarında levofloksasin ve trimetrophimsulfametaksazol duyarlılıkları $\% 100$ olarak belirlenirken, seftazidim duyarlılığı düşük olup \%28,6 olarak bulunmuştur (Tablo 6).

Tablo 6. Stenotrophomonas maltophilia türü bakterilerin
antibiyotik duyarlııkları

P. aureginosa suşlarında amikasin, kolistin ve siprofloksasin duyarlıı̆̆ı \%100 olarak bulunmuştur (Tablo 7).

\begin{tabular}{|c|c|c|}
\hline \multirow{2}{*}{$\begin{array}{l}\text { Pseudomonas aeruginosa } \\
11 \text { adet }\end{array}$} & \multicolumn{2}{|c|}{ Duyarlı suş } \\
\hline & $\mathrm{n}$ & $(\%)$ \\
\hline Amikasin & 11 & 100 \\
\hline Imipenem & 6 & 54,5 \\
\hline Kolistin & 11 & 100 \\
\hline Meropenem & 6 & 54,5 \\
\hline Piperasilin / Tazobaktam & 7 & 63,6 \\
\hline Sefepim & 8 & 72,7 \\
\hline Seftazidim & 8 & 72,7 \\
\hline Siprofloksasin & 11 & 100 \\
\hline
\end{tabular}

Bir adet suşu çalışılan Haemophilus influenza ise duyarlılı̆ına bakılan tüm antibiyotiklere karşı \%100 duyarlı bulunmuştur (Tablo 8). 


\begin{tabular}{|c|c|c|}
\hline \multirow{2}{*}{$\begin{array}{l}\text { Haemophilus influenza } \\
1 \text { adet }\end{array}$} & \multicolumn{2}{|c|}{ Duyarlı suş } \\
\hline & $\mathrm{n}$ & $(\%)$ \\
\hline Ampisilin & 1 & 100 \\
\hline Meropenem & 1 & 100 \\
\hline Seftriakson & 1 & 100 \\
\hline Sefuroksim & 1 & 100 \\
\hline Siprofloksasin & - & 0 \\
\hline
\end{tabular}

\section{Tartışma}

Yoğun bakım ünitelerindeki en önemli sorunlardan biri enfeksiyondur. Enfeksiyon, hastaların yoğun bakım ünitelerine yatış sebebi olabileceği gibi yoğun bakım ünitelerinden de nozokomiyal olarak edinilebilir [11]. Yoğun bakım üniteleri, hastaya yapılan invaziv girişimler, mekanik ventilasyon uygulanması, idrar sondası, damar içi kateter varlığı, periton diyalizkateter varlığı, cerrahi operasyon uygulanması, şant varlığı gibi durumlar nedeniyle enfeksiyon riskinin yüksek olduğu birimlerdir [12,13]. YYBÜ'de yatan bebekler immün sistemleri immatür olduğu ve çoğu zaman altta yatan sebeplerden dolayı invaziv tanı ve tedavi yöntemlerine ihtiyaç duydukları için, birçok enfeksiyon açısından risk altındadırlar [14,15].

Çalışmamız için literatür taraması yaptığımızda yenidoğan yoğun bakım ünitelerindeki hastaları ve Gram negatif bakterileri kapsayan çalışmalara çok fazla rastlanmamıştır. $\mathrm{Bu}$ çalışma literatüre katkı sağlamayı da amaçlamaktadır. Ayrıca çalışmamızda, gerek ülkemizde gerekse yurtdışında yapılmış olan çalışmaların verilerinin karşılaştırılarak YYBÜ'deki direnç durumuna ve etkenlerin dağılımına dikkat çekerek klinisyenlerin mevcut durum hakkında bilgilendirilmesi amaçlanmıştır. Günümüzde direnç yayılımının hızla kurumdan kuruma veya bölgeden bölgeye olabilmesi bu verilerin güncellenmesini zorunlu kılmaktadır.

Renato ve ark.'ın yaptığı YYBÜ'de yatan 6243 hastayı içeren 10 yıllık çalışmada Gram negatif bakteriler içerisinde en çok izole edilen bakteriler Klebsiella spp. $(\% 51,7)$ ve E.coli $(\% 18,8)$ 'dir [16]. Kent ve ark.'ın YYBÜ'de 118 örnekle gerçekleştirdikleri çalışmada en çok izole edilen Gram negatif bakteriler E.coli (\%51), Klebsiella spp. (\%23) ve Enterobacter spp. (\%22)'dir. [17]. Pehlivanoğlu ve ark.'ın çocuk YBÜ (ÇYBÜ) ve YYBÜ'yü dahil ettikleri çalışmada en çok izole ettikleri Gram negatif bakteriler Pseudomonas spp. (\%33)'dir [18]. Orsi ve ark.'ın ÇYBÜ'de yaptığı çalışmada Gram negatif bakteriler içerisinde en sık izole edilen bakteriler K. pneumoniae $(\% 37,7)$ 'dır [19]. Singh ve ark.'ın YBÜ'de yatan hastalardan aldıkları 2920 örnek ile gerçekleştirdikleri çalışmada en çok izole ettikleri Gram negatif bakteriler P. aeruginosa $(\% 38,17)$ ve K. pneumoniae $(\% 23,76)$ 'dır [20]. Bizim çalışmamızda ise en çok izole edilen bakteriler K. pneumoniae $(\% 28,6)$ ve A. baumanii $(\% 23,9)$ olmuştur.

Özçetin ve ark.'nın yaptıkları çalışmada E.coli ve Klebsiella spp. izolatlarında meropenem duyarlılığı sırasıyla \%95,3 ve \%100 oranında saptanmıştır. Pseudomonas spp.'nin en duyarlı olduğu antibiyotiklerin ise meropenem $(\% 85,8)$ ve imipenem $(\% 71,5)$ olduğu saptanmıştır [21]. Minal ve ark.'ın YYBÜ'de kan kültürü pozitif 93 örnekle yaptıkları çalışmada Gram negatif bakterilerden en çok izole edilenler K. pneumoniae $(\% 54,16)$ ve E.coli $(\% 29,16)$ olmuştur. K. pneumoniae izolatlarında en yüksek duyarlılık oranları polimiksin (\%100), levofloksasin $(\% 88,4)$ ve imipenemde $(\% 76)$ görülmüştür. E.coli izolatlarında da en yüksek duyarlılık oranları polimiksin (\%100), levofloksasin $(\% 92,85)$ ve imipenemde (\%94) görülmüştür [22]. Şirin ve ark.'ın YBÜ'de yaptıkları 722 P. aeruginosa izolatını kapsayan çalışmada, en yüksek direnç oranları piperasilin - tazobaktam (\%64), imipenem $(\% 50,2)$ ve meropenemde $(\% 51,9)$ görülmüştür [23]. Lee ve ark.'nın ÇYBÜ'de yaptıkları, 1163 klinik izolat içeren çalışmada Gram negatiflerde P. aeruginosa, E. coli, Klebsiella pneumoniae en yüksek oranda izole edilmiştir. P. aeruginosa izolatlarının \%34'ü karbapeneme dirençli olarak saptanmıştır [24]. Bizim çalışmamızda ise bu çalışmalara paralel olarak Enterobacteriacea üyesi bakterilerde karbapenem duyarlılığı yüksek bulunmuştur. Kaya ve ark.'nın ÇYBÜ'de kan kültürlerinden izole edilen bakterileri inceledikleri çalışmalarında Acinetobacter suşlarının trimethoprim / sulfamethoxazole karşı duyarlılığı \%75 olarak bulunmuştur [25]. Bizim çalışmamızda ise Acinetobacter suşlarının trimethoprim/sulfamethoxazole duyarlılığı ise \%94,4 olarak bulunmuştur. Trimethoprim/sulfamethoxazol dışında Acinetobacter suşlarında tigesiklin duyarlılığı \%80,3 ve kolistin duyarlılığı \%100 olarak bulunmuştur. Acinetobacter suşlarının bu üç antibiyotik dışındaki tüm antibiyotiklere özellikle karbapenemlere karşı oldukça düşük duyarlılık gösterdikleri tespit edilmiştir.

Sonuçolarak, özellikle çoklu antimikrobiyal direncinin sık olarak görüldüğü YYBÜ gibi kliniklerde aktif sürveyans uygulanarak üreyen mikroorganizmalar ve antimikrobiyal duyarlılıklarının takip edilmesinin gerekli olduğu görünmektedir.

\section{Maddi Destek ve Çıkar İlişkisi}

Çalışmayı maddi olarak destekleyen kişi/kuruluş yoktur ve yazarların çıkara dayalı bir ilişkisi yoktur. 


\section{Kaynaklar}

1. Nafziger DA, Lundstrom T, Chandra $S$, Massanari RM. Infection control in ambulatory care. Infect Dis Clin North Am 1997; 2: 279-96.

2. PERK Y. Yenidoğan Yoğun Bakım Enfeksiyonları; Korunma ve Kontrol. i..Ü. Cerrahpaşa Tıp Fakültesi Sürekli Tıp Eğitimi Etkinlikleri. Sempozyum Dizisi No: 60 Ocak 2008; s.137-141.

3. Turkish Neonatal Society, Nosocomial Infections Study Group. Nosocomial infections in neonatal units in Turkey: epidemiology, problems, unit policies and opinions of healthcare workers. Turk J Pediatr 2010; 52: 50-7.

4. Parlak E, Kahveci H, Alay HK; Nosocomial Infections in Neonatal Intensive Care Unit. J Curr Pediatr 2014; 12: 1-8.

5. Özsüt H. Yoğun bakım ünitesinde enfeksiyon sorunu: Dirençli bakteriler ve antibiyotik kullanımı. Hastane İnfeksiyonları Dergisi 1998; 2: 5-14.

6. Gür $D$, Ünal $S$ ve ark. Yoğun bakım ünitelerinden izole edilen gram-negatif bakterilerin çeşitli antibiyotiklere in vitro duyarlılıkları. Flora Dergisi 1996; 3: 153-9.

7. Jarlier V, Fosse T, Philippon A and the ICU study group. Antibiotic suspectibility in aerobic gram-negative bacilli isolated in intansive care units in 39 French teaching hospitals (ICU study). Intensive Care Med 1996; 22: 1057-65.

8. Hanberger $H$, Rodriquez JAG, Gobernado $M$, et al. Antibiotic susceptibility among aerobic gram-negative bacilli isolated in intensive care units in 5 European countries. JAMA 1999; 281:67-71.

9. Uzel S, Özsüt $H$, Eraksoy $H$, Dilmener $M$, Çalangu. S. Yoğun bakım biriminde ventilatörle ilişkili pnömoni etkeni olabilecek bakterilerin dağılımı ve antibiyotiklere duyarlııkları. Klimik Derg 1996; 9: 6-9.

10. Leblebicioğlu H, Nas $Y$, Günaydın M, Saniç A, Akçam Z. Yoğun bakım servisindeki hastalardan izole edilen gram-negatif patojenlerin beta-laktam antibiyotiklere direnç durumu. Klimik Derg 1996; 9: 10-2.

11. İnce E. Rational Antibiotic Use In Pediatric Intensive Care Units. Turkiye Klinikleri J Pediatr Sci 2005; 1: 96-100.

12. Özçetin M, Saz E, Karapınar B, Özen S, Aydemir Ş, Vardar F. Hastane Enfeksiyonları; Sıklığı ve Risk Faktörleri. Çocuk Enf Derg 2009; 3: 49-53.

13. Çelik İnci N, Denk A, Sevim E, Yaflar D, Yaflar MA. Prevalence of Hospital Acquired Infections in Anesthesiology Intensive Care Unit. Fırat Tıp Dergisi 2005; 10: 132-5.

14. Babazono A, Kitajima H, Nishimaki S, et al. Risk factors fornosocomial infection in the neonatal intensive care unit by the Japanese Nosocomial Infection Surveillance (JANIS). Acta Med Okayama 2008; 62: 261-8.
15. Asembergiene J, Gurskis V, Kevalas R, Valinteliene R. Nosocomial infections in the pediatric intensive care units in Lithuania. Medicina (Kaunas) 2009; 45: 29-36.

16. Couto RC, Carvalho EA, Pedrosa TM, Pedroso ER, Neto MC, Biscione FM. A 10-year prospective surveillance of nosocomial infections in neonatal intensive care units. Am J Infect Control 2007; 35: 183-9.

17. Kent A, Kortsalioudaki C, Monahan IM, et al. Neonatal gramnegative infections, antibiotic susceptibility and clinical outcome: an observational study. Arch Dis Child Fetal Neonatal Ed 2016; 0: F1-F6.

18. Pehlivanoğlu F, Yaşar KK, Gürsoy S, Şengöz G, Ataoğlu E, Karakuş A. Çocuk ve Yenidoğan Yoğun Bakım Ünitesinde Antibiyotik Direnci Deneyimi. Med Bull Haseki 2011; 49: 30-33.

19. Orsi GB, d'Ettorre G, Panero A, Chiarini F, Vullo V, Venditti M. Hospital-acquired infection surveillance in a neonatal intensive care unit. Am J Infect Control 2009; 37: 201-3.

20. Singh $A A$, Kaur $M$, Singh $A$, et al. Prevalence of microbial infection and strategic pattern of antimicrobial resistance among intensive care unit patients in a tertiary care teaching hospital from rural Northern India. IAIM 2015; 2: 14-20.

21. Özçetin M, Saz Eu, Karapınar B, Özen S, Aydemir Ş, Vardar F. Hastane Enfeksiyonları; Sıklığı ve Risk Faktörleri. Çocuk Enf Derg 2009; 3: 49-53.

22. Minal T, Vegad MM, Shah PK, Soni S. Study of Gram Negative Organisms in Neonatal Septicaemia and its Antibiotic Susceptibility Pattern. Intl J Microbiol Res 2015; 6: 123-9.

23. Şirin $M C$, Ağuş $N$, Yılmaz N, et al. Yoğun bakım ünitelerinden izole edilen Pseudomonas aeruginosa ve Acinetobacter baumannii suşlarında antibiyotik direnç profillerinin yıllar içindeki değişimi. J Clin Experiment Invest 2015; 6: 279-85.

24. Lee $C Y$, Chen PY, Huang FL, Lin CF. Microbiologic spectrum and susceptibility pattern of clinical isolates from the pediatric intensive care unit in a single medical center - 6 years' experience. J Microbiol Immunol Infect 2009; 42: 160-5.

25. Kaya S, Arıdoğan BC, Çetin H, Demirci M. Çocuk hastalardan alınan kan kültürlerinde üreyen mikroorganizmalar ve antibiyotik dirençleri. Fırat Tıp Dergisi 2007; 12: 34-36. 